\title{
Leprosy and tuberculosis in the Blue Nile Valley of Western Ethiopia
}

\author{
S G GUNDERSEN* \\ Mendi Clinic, Mendi, Welega Region, Ethiopia \\ Accepted for publication 6 August 1986
}

\begin{abstract}
Summary Data are presented on the prevalence of leprosy and tuberculosis among different ethnic groups living under different environmental conditions in the Mendi district of the Blue Nile Valley, Western Ethiopia. The data are based on a clinical survey of 1323 persons (main study), representing Highland and Midland Oromos as well as Midland and Lowland Nilotics and on records from the local leprosy and tuberculosis programmes (additional study). It is concluded that cases of leprosy are rarely found in the highlands, whereas prevalences of 53/1000 and $92 / 1000$, respectively, were found in two of the Lowland Nilotic villages. On the other hand, tuberculosis is 2-4 times more frequent among the Highland and Midland Oromo population (10-18/1000) than among the Midland and Lowland Nilotics (3-7/1000). In addition to the genetic difference between the Oromo and Nilotic populations, the higher temperatures, lower humidity and black soil observed at the lower altitudes might be of importance for the prevalence of mycobacterial disease. There is some evidence of an ongoing leprosy epidemic among the previously isolated Lowland Nilotics, and indications of a tuberculosis epidemic starting after their increased contact with the tuberculosis-infested Highland Oromos.

This paper is the first in a series that reports on the prevalences of several public health problems in this area, the Blue Nile Public Health Survey (BNPHS). Hence, some general information is provided on the concerned population, the geography and the organization of the public health services in the Mendi district.
\end{abstract}

\section{Introduction}

Interactions between $M$. leprae and related mycobacteriae are important features of leprosy epidemiology, and special attention has been paid to the possible epidemiological antagonism between leprosy and tuberculosis. ${ }^{1-6}$ BCG vaccination may provide some protection against leprosy, and crossed immunization has also been demonstrated by skin tests. ${ }^{1-12}$ Some studies ${ }^{3,5,12}$ suggest that the relative distribution of these major human pathogens is influenced by ecological factors such as altitude, temperature and annual rainfall as well as ethnic

* Present address: Department of Infectious Diseases, Ullevaal University Hospital, 0407 Oslo 4, Norway. 
background and density of population. In order to identify such factors the logical target for investigations appear to be areas where both tuberculosis and leprosy are prevalent.

Preliminary information (Soerensen, I., personal communication) from the Mendi district of Western Ethiopia indicated that leprosy was defined to the lower altitudes, whereas tuberculosis was mainly found in the highlands. The present study was initiated to provide more reliable information on the distribution of leprosy and tuberculosis among representatives of the Mendi lowland, midland and highland, respectively.

In addition to the scientific value of such studies, the investigation was required to identify priorities within the Blue Nile Public Health Project.

\section{Materials and methods}

\section{LAND, PEOPLE AND HEALTH CARE}

The Mendi District is an administrative unit of about 100,000 inhabitants (1980) within Welega, the westernmost region of Ethiopia (Figure 1). The Blue Nile constitutes the northern border of the district running north-westwards at an altitude of about $700 \mathrm{~m}$. From the river lowlands the country rises towards the south up to the main Mendi highland plateau, about $1700 \mathrm{~m}$ above sea level. In the middle of the slopes, at an altitude of about $1200 \mathrm{~m}$, are the flat plains of Dalati, here called the midlands.

The lowlands are an extension of the Sudanese savannah with some forest galleries in the hillsides. ${ }^{13}$ The soil is black and fertile, the mean temperature is high and during the dry season maximum temperatures of $40-45^{\circ} \mathrm{C}$ are common. Mean annual precipitation is $800-1000 \mathrm{~mm} \cdot{ }^{13}$ There are no complete meteorological data available from this outpost area.

The main inhabitants are hoe-cultivating Nilotic tribes living in villages of small bamboo huts. Each family owns several huts which vary in size from 4 to $30 \mathrm{~m}^{2}$, with an average of about $15 \mathrm{~m}^{2}$. An average of 5 people sleep in each hut.

Hens and goats are common, but cattle scarce due to zoonotic trypanosomiasis. Meat from hunting is sometimes added to the diet, which otherwise is based on fermented porridge of sorghum with a spiced vegetable sauce.

There is widespread social contact between the Nilotic villages. Around the major lowland village of Sirba lives the previously very isolated Saysay tribe of the Nilotic Gumuz people ${ }^{13,14}$, in this survey called the Lowland Nilotics.

The highlands of the Mendi district are mainly eroded mountain savannah with vulcanic red soil of low fertility. ${ }^{13}$ In 1984 the average maximum temperature was $28.7^{\circ} \mathrm{C}$ and the average minimum temperature $15.0^{\circ} \mathrm{C}$. The total annual precipitation in the same year was $1.754 \mathrm{~mm}$, mainly falling from April to October. 


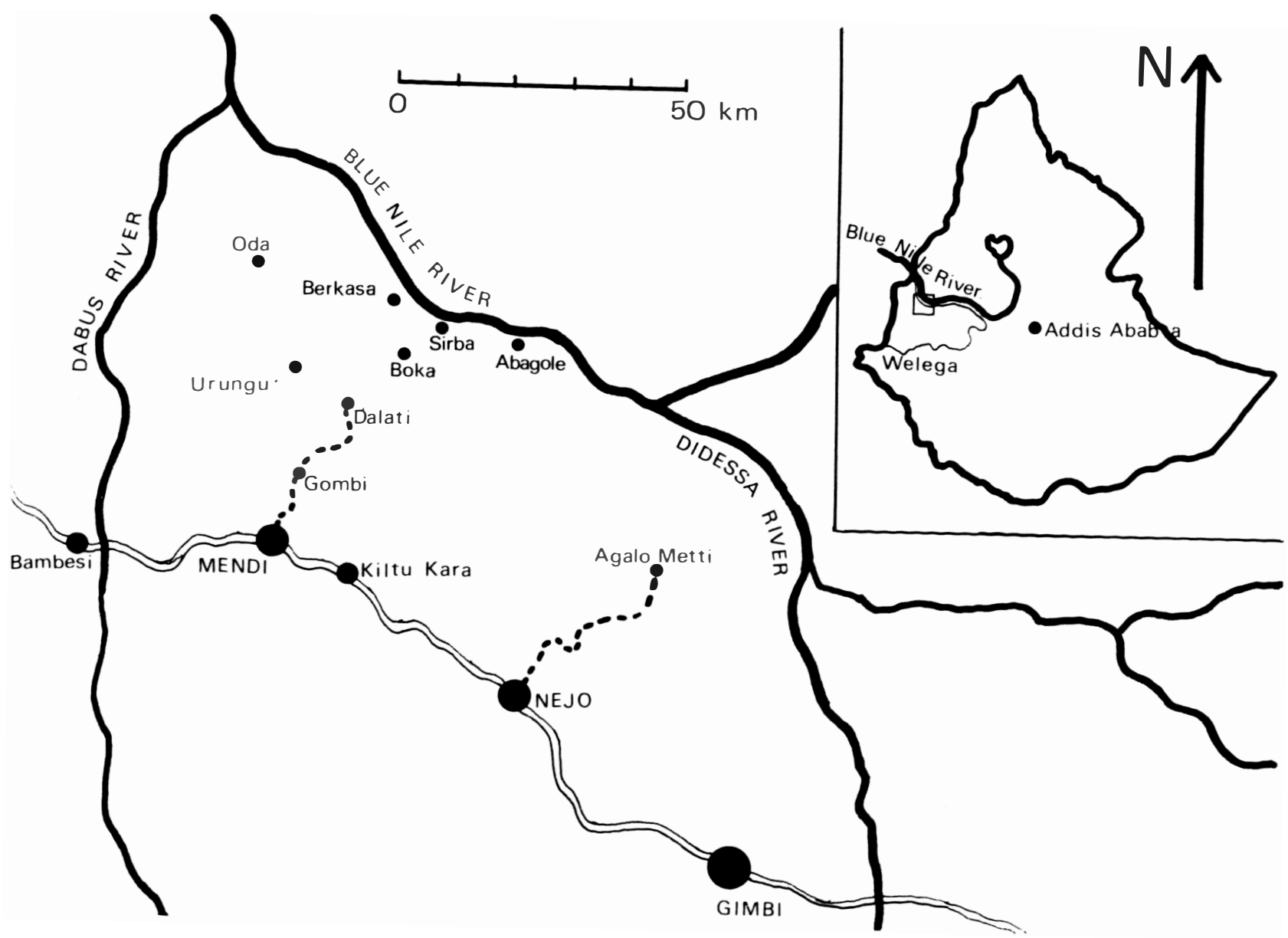

Figure 1. Map of the study area within the Mendi district of Western Ethiopia. 
The main inhabitants are plough-cultivating Oromo people of Cushitic origin. ${ }^{13,15}$ They live in clusters of houses made of dried mud. The average family consists of about 10 members. In most cases each family owns only one house approximately 15 to $45 \mathrm{~m}^{2}$, usually with more than one room.

The main staple food consists of a fermented pancake of teff (a small, iron-rich crop exclusively found in Ethiopia) or maize with a spiced sauce of vegetables. Meat is eaten occasionally. The Oromos keep cattle, sheep and hens, but do not hunt or fish.

There is only occasional social contact between villages. The Highland Oromos live permanently in the highlands, while the Midland Oromos leave their original highland villages for about 6 months yearly to do farming at the lower altitudes around Dalati.

The midlands derive geographical and population characteristics from both areas. The area is relatively hot with maximum temperatures between 30 and $40^{\circ} \mathrm{C}$. Complete meterological details are not available, but daily registrations have now been started. In 1984 the total recorded precipitation was $1,340 \mathrm{~mm}$. The soil is fertile, changing from red to black. The original inhabitants are Nilotics of the Bertha group (Midland Nilotics), differing from the lowland Gumuz groups mainly by language. ${ }^{13,16}$ In addition, a considerable number of Midland Oromos stayed in the midlands at the time of investigation.

Communication. The roads in the area are scarce. Between Mendi and Dalati there is a track passable by 4 -wheel drive vehicles. At the time of the survey further travel had to be by foot or mule. Since 1982 4-wheel drive cars may pass from Dalati to Sirba during the dry season.

The health services of the district are coordinated from the Mendi clinic or health centre, which is staffed with 1 physician, 2 nurses and 4-6 health assistants. The physician supervises a public health team consisting of 1 nurse, 1 health assistant and 1 epidemiology worker. In addition to the community health activities offered by this team, permanent health service is provided in the lowlands by $2-3$ health workers at the small clinic in Dalati. The primary health care in the villages is to an increasing extent given by community health agents and traditional birth attendants who receive short training courses.

\section{MAIN STUDY POPULATION}

The total population of the Mendi district is approximately 100,000 of whom the lowland, midland and highland represent 5,5 , and $90 \%$ respectively. The choice of study population was made primarily to cover ethnic and cultural groups typical of the respective altitude and not to give representative samples of the whole district. Also accessibility to the villages and the attitude of village elders upon a preliminary request of cooperation influenced the decision.

In May 1982, 1,323 persons were examined for clinical and/or laboratory evidence of selected infectious diseases and malnutrition. The survey population was distributed by ethnic origin and altitude of settlement as follows: 
a, 393 Highland Oromos from Gombi (1700 m); b, 455 Midland Oromos from Dalati $(1200 \mathrm{~m})$; c, 193 Midland Nilotics from Dalati $(1200 \mathrm{~m})$; and d, 282 Lowland Nilotics from Sirba $(700 \mathrm{~m})$.

Local elders and teachers ensured that every household member attended, once the head of the family had agreed. In the villages approached, the percentage of participation averaged $35 \%(20-50 \%)$. The age and sex distribution of the 1323 persons examined is given in Figure 2. Except for some overrepresentation of persons (mostly females) aged 30-40, and children (mostly boys) below the age of 10 , the survey population pyramid is similar to that of the total population of the district.

The results of the leprosy and tuberculosis investigation will be given here, while the prevalence of intestinal parasites, onchocerciasis, trachoma, malaria and malnutrition will be reported elsewhere.

A. Survey population

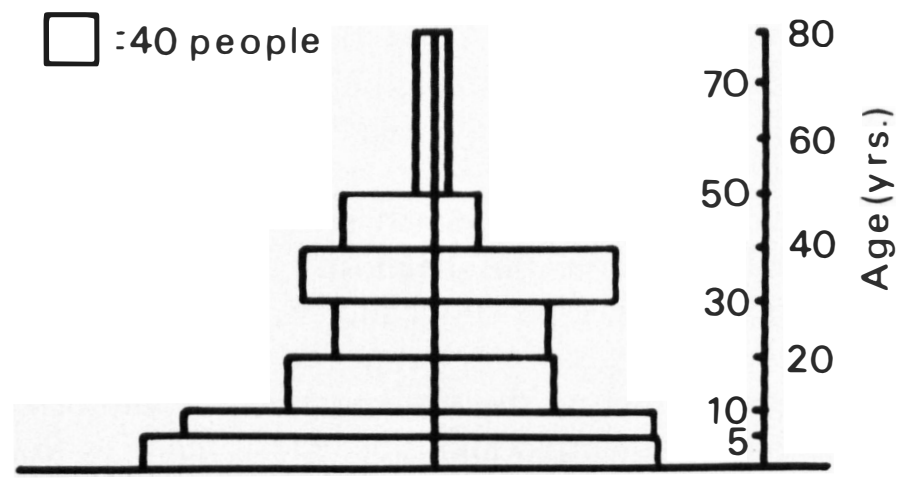

B. Total District population

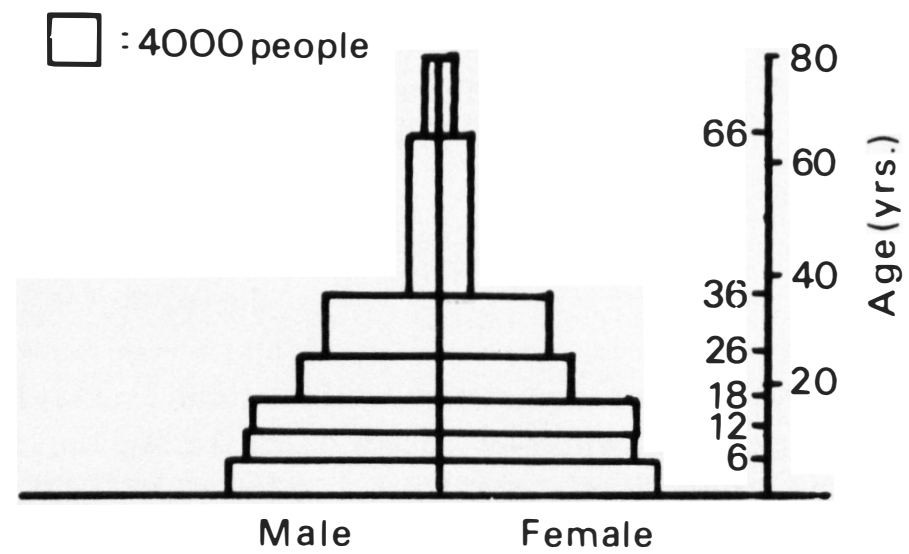

Figure 2. Population pyramid by sex and age for: (a) main study population (total 1323); and (b) total Mendi district population according to registration of 1980 (total 102,499). 
ADIDITIONAL STUDY POPULATION

All patients already registered in current leprosy and tuberculosis programmes of the Mendi district were included in this study. Because both studies were made in the same geographical area, there was some accidental overlapping of the main and the additional study population, which will be commented on later.

\section{DIAGNOSIS ANI) CLASSIFICATION}

We adopted the procedures for diagnosis and classification that had so far been used in the local programmes, which conform to what is traditionally used in rural work with limited diagnostic resources.

Leprosy. The diagnosis was based on clinical examination, supplemented by skin smears for microscopy of possible acid-fast bacilli. Skin smear negative cases with one or a few hypopigmented macules without any impairment of sensation and without nerve enlargement were classified as indeterminate. Paucibacillary patients with impaired sensation of lesions and/or enlarged nerves but without major sequelae were listed as tuberculoid cases. All cases showing sequelae from neuritis were grouped as borderline. A few treated initially as multibacillary patients might have been included in this group. As lepromatous leprosy were diagnosed those with multibacillary involvement of the skin with or without nodulation.

Tuberculosis. The diagnosis was primarily given to cases of sputum positive pulmonary tuberculosis. However, this diagnostic group also included pulmonary and extrapulmonary cases, especially children, with typical chronic symptoms that responded to tuberculostatics but not to conventional antibiotics.

Reliability of diagnosis. Before the study started the author evaluated the reliability of the diagnoses of leprosy and tuberculosis made by the experienced nurses and health assistants. For this purpose we thoroughly reviewed the records of the existing leprosy and tuberculosis programmes for the years 1980 and 1981 according to the above-mentioned diagnostic criteria. Fifty per cent of the leprosy patients were visited at home and re-examined, while the majority of the tuberculosis patients were re-examined in the clinics.

\section{Results}

\section{MAIN STUDY}

In Table 1 the leprosy results are summarized. Of the total 23 cases (17/1000), 16 were already under treatment, while 7 were new cases. Among the Highland and Midland Oromos we found prevalence rates of 3 and 9 per 1000, respectively. On the other hand, the respective prevalence rates of Midland and Lowland Nilotics were 16 and 53 per 1000 .

Among the Lowland Nilotics 3 new leprosy cases were diagnosed, while the 3 
Table 1. Main study. Distribution of leprosy cases in the Mendi district according to altitude and ethnic group

\begin{tabular}{lccccc}
\hline Population & In determ. & Tuberculoid Borderline & Lepromatous & $\begin{array}{c}\text { Total } \\
\text { (Prev. rate/100) }\end{array}$ \\
\hline $\begin{array}{l}\text { Highland Oromos } \\
(n=393)\end{array}$ & 1 & 0 & 0 & 0 & $1(3)$ \\
$\begin{array}{l}\text { Midland Oromos } \\
(n=455)\end{array}$ & 3 & 0 & 1 & 0 & $4(9)$ \\
$\begin{array}{l}\text { Midland Nilotics } \\
(n=193)\end{array}$ & 1 & 0 & 1 & 1 & $3(16)$ \\
$\begin{array}{l}\text { Lowland Nilotics } \\
(n=282)\end{array}$ & 1 & 5 & 9 & 0 & $15(53)$ \\
\hline $\begin{array}{l}\text { Total } \\
(n=1323)\end{array}$ & 6 & 5 & 11 & 1 & $23(17)$ \\
\hline
\end{tabular}

patients found among the Midland Nilotics were already under treatment. The tuberculoid end of the spectrum represented $48 \%$ of the total number of leprosy patients found in the survey.

Table 2 shows the distribution of suspected and proven tuberculosis cases found during the survey. Of totally 1323 people examined, 74 (56/1000) were suspected of tuberculosis on clinical grounds. Of these $38(51 \%)$ came for further examination in one of the clinics. Seventeen of these were proven to have tuberculosis by sputum microscopy or cure by tuberculostatic treatment. Of the 17 proven cases 6 had previously recognized tuberculosis, 3 were on treatment while 3 were defaulters. Table 2 also demonstrates the high prevalence of tuberculosis among the Oromos of the higher altitudes. While only 1 of the 193

Table 2. Main study. Distribution of suspected and proven tuberculosis in the Mendi district according to altitude and ethnic group

\begin{tabular}{lccc}
\hline & \multicolumn{1}{c}{$\begin{array}{c}\text { Suspected } \\
\text { Pumber } \\
\text { tuberculosis } \\
\text { examined }\end{array}$} & $\begin{array}{c}\text { Proven } \\
\text { (tuberculosis } \\
\text { (Prev. rate/1000) }\end{array}$ \\
\hline Highland Oromos & 393 & $44(112)$ & $7(18)$ \\
Midland Oromos & 455 & $20(44)$ & $7(15)$ \\
Midland Nilotics & 193 & $8(41)$ & $1(5)$ \\
Lowland Nilotic & 282 & $2(7)$ & $2(7)$ \\
\hline Total & 1323 & $74(56)$ & $17(13)$ \\
\hline
\end{tabular}


Midland Nilotics (5/1000) and 2 of the 282 Lowland Nilotics (7/1000) had tuberculosis, 7 of 393 Highland Oromos (18/1000) and 7 of 455 Midland Oromos $(15 / 1000)$ were found to suffer from this disease.

\section{ADIDITIONAL STUDY}

While only 1 leprosy patient was registered in the highland, 105 were registered at the Dalati clinic, serving midland and lowland population. Of these 105,50 were re-examined by the author, and all had their diagnosis confirmed. Four had indeterminate, 22 tuberculoid, 22 borderline and 2 lepromatous leprosy, which gives a type prevalence at the tuberculoid end of the spectrum (indeterminate plus tuberculoid cases) of $52 \%$. Of these 50,34 claimed to have got their first patch above 30 years of age. In 14 of the 50 patients a total of 24 sequelae were registered, including infected wounds on hands (3) and feet (3), loss of fingers (8) and toes (2), clawhand (3) and other muscle atrophy of hand (3), lagophtalmos (2).

The majority (94) of the 106 leprosy patients registered in the total district inhabited six midland or lowland villages (see Figure 1) with a total population of 2405 , which gives a prevalence rate of 39 per 1000 . Table 3 shows the distribution of cases on these six villages. For three of the villages in the far lowland, Sirba Abaya, Boka Wau and Abagole Kuseru, the very high prevalences of 53, 73 and 92 per thousand respectively, were found.

Table 3. Additional study. Distribution of leprosy patients on six hyperendemic Nilotic villages in the Blue Nile Valley according to the local leprosy and tuberculosis control programmes of the Mendi district

\begin{tabular}{lccc}
\hline Village & $\begin{array}{c}\text { Number of* } \\
\text { inhabitants }\end{array}$ & $\begin{array}{c}\text { Number of } \\
\text { leprosy cases }\end{array}$ & $\begin{array}{c}\text { Prevalence rate } \\
\text { per thousand }\end{array}$ \\
\hline Sirba Abaya & 759 & 40 & 53 \\
Abagole Kuseru & 272 & 25 & 92 \\
Boka Wau & $220+$ & 16 & 73 \\
Berkasa Mercha & 407 & 7 & 17 \\
Urungu & 235 & 4 & 17 \\
Dalati & 512 & 2 & 4 \\
\hline Total & 2405 & 94 & 39 \\
\hline
\end{tabular}

* Figures obtained from the official district registration for 1980.

+ Because the figure for Boka Wau was lacking in the register, the number of inhabitants was calculated from the number of houses (44) multiplied by 5 . 
In Table 4 the prevalence rates for both leprosy and tuberculosis are summarized for the different parts of the Mendi district. Of the 11 leprosy patients registered outside the six hyperendemic villages, 5 were Oromos and 6 were Nilotics, all living in the midland or lowland area.

Only 6 tuberculosis patients were found among the 2405 inhabitants of the six leprosy dominated villages (3/1000). By contrast 71 of $5557(13 / 1000)$ and 10 of $1024(10 / 1000)$ inhabitants of the highland towns of Mendi and Kiltu Kara respectively, were registered as tuberculosis patients under treatment. Among the remaining rural Mendi district population of 93513 a total of 236 cases of tuberculosis were registered $(3 / 1000)$.

Table 4. Additional study. Prevalence rates for leprosy and tuberculosis in different parts of Mendi district according to the local leprosy and tuberculosis control programme

\begin{tabular}{lccc}
\hline & Number of* & $\begin{array}{c}\text { Number of } \\
\text { leprosy cases } \\
\text { Area }\end{array}$ & $\begin{array}{c}\text { Number of } \\
\text { inhabitants }\end{array}$ \\
$\begin{array}{l}\text { tuberculosis cases } \\
\text { (Prev. rate/1000) }\end{array}$ \\
$\begin{array}{l}\text { Six mid- and lowland } \\
\text { Nilotic villages }\end{array}$ & 2,405 & $94(39)$ & $6(3)$ \\
Mendi Town & 5,557 & $1(-)$ & $71(13)$ \\
Kiltu Kara Town & 1,024 & $0(-)$ & $10(10)$ \\
Remaining district & 93,513 & $11(-)$ & $236(3)$ \\
\hline Total & 102,499 & $106(1)$ & $323(3)$ \\
\hline
\end{tabular}

* Figures obtained from the official Mendi district registration for 1980.

\section{Discussion}

In Ethiopia at large the estimated average prevalence rate for leprosy is 10/1000, and the highest local rates so far published (25-49/1000) are from the highlands of Gojjam north of Welega. ${ }^{13}$ Systematic review of the records of the current leprosy programme (additional study population) clearly indicated a difference in the prevalence of leprosy between the highland and lowland populations of the Mendi district. Among the highland Oromos leprosy was very rare $(0 \cdot 2 / 1000)$ while an average prevalence rate of $39 / 1000$ was found in six of the Nilotic lowland villages. In fact, rates as high as 53/1000, 73/1000 and 92/1000 were calculated for three of the most affected villages in the lowlands. Our investigation of the main study population confirmed that leprosy is now common among the lowland Nilotics with an average rate estimated at 53/1000, 
which is far above the prevalence $(5 / 1000)$ found by Fullar Torrey in $1966 .{ }^{17}$ Moreover, 4 of the 5 cases found among the 848 Oromos were classified as indeterminate leprosy, which remains a rather inconclusive diagnosis. The low prevalence rate of leprosy in the genuine highland population is further underlined by the fact that 5 out of the 6 Oromos included in the control programme lived in the midlands most of the year.

The average prevalence of tuberculosis in Ethiopia has been estimated at $1 \%$, although rates up to $5 \%$ have been recorded. ${ }^{13}$ In the Mendi clinic, serving mainly a population of about 100,000 inhabitants, an average of 50-100 new sputum positive cases are diagnosed annually. According to experiences from similar programmes this corresponds to an annual incidence rate of tuberculosis of $1 \%{ }^{18}$ Due to the limitations of this laboratory technique, insufficient medical coverage and a high defaulter rate, the true prevalence of tuberculosis in the Mendi district is certainly much higher. Interestingly, the distribution of tuberculosis within the district differed sharply from that of leprosy: among the lowland Nilotics the prevalence of tuberculosis was estimated at 3-7/1000 whereas the corresponding rate among the Oromos of the highlands was 10-18/1000. Similar differences between lowland and highland areas as regards the prevalence of tuberculosis have been reported from Erithrea. ${ }^{19}$ On the other hand Reynolds ${ }^{20}$ in 1963 found very high rates of clinical tuberculosis and skin reactivity among Nilotic Annuak people of Gambela, a lowland area of South Western Ethiopia.

Prevalence rates may vary considerably according to population density, as reported from South Western Ethiopia. ${ }^{21}$ However, the clearly significant difference between the prevalence observed in the six Nilotic midland and lowland villages (3/1000) and that of Mendi town (13/1000) is not easily explained by factors such as density of housing or social and cultural habits. Also, the medical services delivered by local clinics are available to the same extent in Dalati/Sirba and in the Mendi town. On the other hand the very low prevalence found in the remaining district might simply reflect insufficient medical coverage in the remote areas.

The previous distribution of mycobacterial diseases in the Mendi district could possibly have been a consequence of immunological interplay between leprosy and tuberculosis as well as differences in altitude, temperature, annual rainfall, soil characteristics and ethnic background. ${ }^{1-12}$ Our survey, however, has disclosed a more complex pattern: in the highlands, a previously endemic situation for leprosy now seems to be overshadowed by the high tuberculosis prevalence. Furthermore, among the lowland Nilotics, there is evidence of an ongoing leprosy epidemic ${ }^{22-26}$ and indications of a startling increase in tuberculosis prevalence compared to the absence of this disease found in $1966 .{ }^{17}$ Thus, if natural interplay between mycobacteria plays a role, it certainly does not seem to be a static feature of mycobacterial epidemiology. ${ }^{25}$ More likely, the occasional introduction of one of these diseases into rather isolated populations may explain the uneven distribution of mycobacterial diseases..$^{22-25}$ Thus, the apparent rapid 
increase of tuberculosis among lowland Nilotics may simply be explained by increasing contact of this traditionally isolated population with the highland Oromos, where tuberculosis is widespread.

Large field trials evaluating the protective effect of BCG against leprosy and tuberculosis have shown conflicting results. ${ }^{27} 28$ Repeated surveys using tuberculin and lepromin skin testing, ${ }^{29-32}$ followed by appropriate examination and, if required, treatment of positive cases, might therefore be more effective in the control of tuberculosis and leprosy than the BCG vaccination programme already launched in parts of this area.

\section{Acknowledgments}

The national and regional departments of leprosy and tuberculosis control of the Ethiopian Ministry of Health and the Armauer Hansen Research Institute are acknowledged for their encouragement and help during the survey period. I also want to thank Professor B Bjorvatn (Oslo/Bergen), Dr G Bjune (Addis Ababa/ Oslo), Professor M Harboe (Oslo) and Professor O Aalen (Oslo) for valuable suggestions in the planning and for the manuscript.

Last, but not least, my appreciation goes to the medical personnel of the Mendi district who made the survey possible.

\section{References}

1 Chaussinand R. Tuberculose et lepre, maladies antagoniques. Int $J$ Lepr, 1948; 16: 431-8.

2 Fernandez JMM. Leprosy and tuberculosis. AMA Arch Derm, 1957; 75: 101-6.

${ }^{3}$ Fine P. Leprosy and tuberculosis - an epidemiological comparison. Tubercle, 1984; 65: 137-53.

${ }^{4}$ Grounds JG. Leprosy and tuberculosis: A statistical relation in South Nyanza, Kenya. $J$ trop Med Hyg, 1964; 67: 13-5.

${ }^{5}$ Hunter JM, Thomas MO. Hypothesis of leprosy, tuberculosis and urbanization in Africa. Soc Sci Med, 1984; 19: 27-57.

${ }^{6}$ Nelson GS. Leprosy in the West Nile District of Uganda: An epidemiological study with special reference to the distribution of leprosy in Africa Trans Roy Soc trop Med Hyg, 1958; 52: 176 85.

7 Castro NO. Sensitization to lepromin induced experimentally with BCG. Int J Lepr, 1952; 20: $221-8$.

8 Davey TF, Drewett SE. Tuberculin and lepromin sensibility in E. Nigeria. Lepr Rer, 1958; 29: 81-101.

${ }^{9}$ Hale JH, Moleworth BD, Grove-White RJ, Sambamurthi CM, Russell DA. The relationship and significance of mantoux and lepromin reactions in leprosy. Int $J$ Lepr, 1955; 23: 139-47.

${ }^{10}$ Leiker DL. Studies on lepromin test. Int J Lepr, 1961; 29: 488-95.

11 Muir E. Relationship of leprosy and tuberculosis. Lepr Rev, 1957; 28: 11-9.

12 Irgens LM. Leprosy in Norway. Lepr Rev, 1980; (Suppl. 1), 51: 1-130.

13 Schaller KF, Kuls W. Ethiopia. A Geomedical Monograph. Berlin, Heidelberg, New York: Springer Verlag, 1972. 
14 Irwin L. Some notes on Saysay culture. J Ethiop Stud, 1968; 6: 131-9.

is Ferguson CA. The Ethiopian language area. J Ethiop Stud, 1970; 8: 67-80.

th Unseth P. Unpublished report. 1984.

17 Fuller Torrey E. A medical survey of the Saysay people in the Blue Nile Gorge. Ethiop Med J, 1966; 15: 155-9.

18 Styblo K. The present epidemiological situation of tuberculosis in developing countries. WHO/ TB/82.135, 1982.

19 Perry A. Tuberculosis in Eritrea. Ethiop Med J, 1963; 2: 31-5.

20) Reynolds D. The tuberculosis problem in Gambela District, Illubabor Province. Ethiop Med J, 1963; 2: 36-8.

${ }^{21}$ Fuller GK, Gemeda N, Fuller D, Demerest V. A tuberculin skin test survey in Southwestern Ethiopia. Trop Geogr Med, 1979; 31: 365-73.

22 Davey TF. Decline of leprosy in a group of Nigerian villages between 1941 and 1956. Int J Lepr, 1957; 25: 329-44.

23. Davey TF, Ross CM. Leprosy: A changing situation in Eastern Nigeria. Brit Med J, 1956; 2: 658.

${ }^{24}$ Leiker DL. Epidemiological and immunological surveys in Netherlands New Guinea. Lepr Ret, 1960; 31: 241-59.

${ }^{25}$ Skinsnes OK. Immuno-epidemiology of leprosy. Editorial. Int J Lepr, 1975; 43: 145-8.

${ }^{26}$ Wade HW, Ledowsky V. The leprosy epidemic at Nauru: A review with data on status since 1937. Int J Lepr, 1952; 20: 1-29.

27 Editorial. BCG: Bad news from India. Lancet, 1980; 1: 73-4.

28 Noordeen SK, Sansarricq H. Immunization against leprosy: progress and prospects. Bull WHO, 1984; 62: 1-6.

29 Paul RC, Stanford JL. Multiple skin testing in leprosy. J Hyg Camb, 1975; 75: 57-68.

${ }^{30}$ Shield MJ, Stanford JL, Paul RC. Multiple skin testing of tuberculosis patients with a range of new tuberculins, and a comparison with leprosy and Mycobacterium ulcerans infections. $J$ Hyg Camb, 1977; 78: 331-48.

31 Stanford JL, Nye PM, Rook GAW, Samuel N, Fairbank A. A preliminary investigation of responsiveness or otherwise of patients and staff of a leprosy hospital to groups of shared or species specific antigens of mycobacteria. Lepr Rev, 1981; 52: 321-7.

32 Stanford JL. Skin testing with mycobacterial reagents in leprosy. Tubercle, 1984; 65: 63-74. 